Provided for non-commercial research and education use. Not for reproduction, distribution or commercial use.

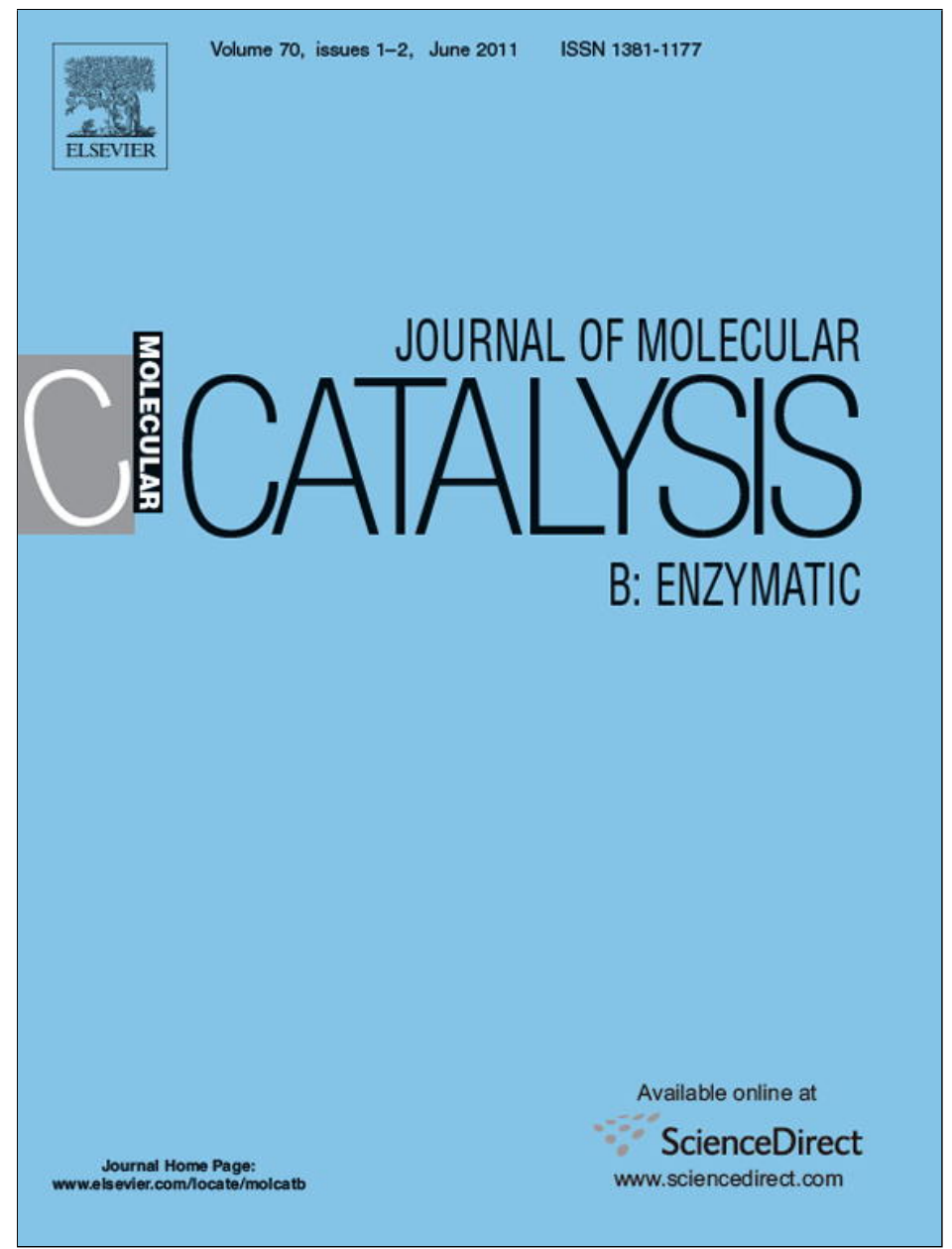

This article appeared in a journal published by Elsevier. The attached copy is furnished to the author for internal non-commercial research and education use, including for instruction at the authors institution and sharing with colleagues.

Other uses, including reproduction and distribution, or selling or licensing copies, or posting to personal, institutional or third party websites are prohibited.

In most cases authors are permitted to post their version of the article (e.g. in Word or Tex form) to their personal website or institutional repository. Authors requiring further information regarding Elsevier's archiving and manuscript policies are encouraged to visit:

http://www.elsevier.com/copyright 


\title{
Asymmetric preparation of antifungal 1-(4'-chlorophenyl)-1-cyclopropyl methanol and 1-(4'-chlorophenyl)-2-phenylethanol. Study of the detoxification mechanism by Botrytis cinerea
}

\author{
Cristina Pinedo-Rivilla, Antonio J. Bustillo, Rosario Hernández-Galán, Josefina Aleu*, Isidro G. Collado* \\ Departamento de Química Orgánica, Facultad de Ciencias, Universidad de Cádiz, República Saharaui s/n, Apdo. 40, 11510 Puerto Real, Cádiz, Spain
}

\section{A R T I C L E I N F O}

\section{Article history:}

Received 20 October 2010

Received in revised form 27 January 2011

Accepted 2 February 2011

Available online 24 February 2011

\section{Keywords:}

Botrytis cinerea

Lipase

Baker's yeast

1-(4'-Chlorophenyl)-1-cyclopropyl

methanol

1-(4'-Chlorophenyl)-2-phenylethanol

\begin{abstract}
A B S T R A C T
Chiral alcohols are important as bioactive compounds or as precursors to such molecules. On the basis of the different antifungal properties of the enantiopure alcohol derivatives of $4^{\prime}$-chlorophenyl cyclopropyl ketone and benzyl 4'-chlorophenyl ketone, their enantioselective synthesis by chemical and biocatalytic methods was studied. The detoxification pathways by the phytopathogen fungus Botrytis cinerea are reported.
\end{abstract}

(C) 2011 Elsevier B.V. All rights reserved.

\section{Introduction}

Botrytis cinerea has been identified as a pathogenic fungus associated with over 235 plant species including grapes, lettuce, tomatoes, tobacco, and strawberries. It grows as a grey mould causing serious economic losses [1,2]. Since several strains have developed resistance to some commercial fungicides [3], there is an important need to develop novel antifungal agents that are active against this organism.

On the basis of previous results indicating that the presence of a hydroxyl group was fundamental for the expression of antifungal activity against the phytopathogenic fungus $B$. cinerea [4-7], we showed that the alcohol derivatives of 4 '-chlorophenyl cyclopropyl ketone (1) and benzyl 4'-chlorophenyl ketone (2), compounds analogous to several phytoalexins $[8,9]$, are active fungistatic agents against B. cinerea and Colletotrichum gloeosporioides [10].

The development of highly effective systems for the synthesis of chiral alcohols is not only of interest to the academic world but also has attracted the attention of industrial scientists. Because of their environmentally benign reaction conditions and unparalleled chemo, regio, and stereoselectivities, enzymatic protocols

\footnotetext{
* Corresponding author. Tel.: +34 956 016368; fax: +34 956016193

E-mail addresses: josefina.aleu@uca.es (J. Aleu), isidro.gonzalez@uca.es (I.G. Collado).
}

have been gaining in popularity [11]. In this paper we report on the enantioselective synthesis of 1-(4'-chlorophenyl)-1-cyclopropyl methanol (3) and 1-(4'-chlorophenyl)-2-phenylethanol (4) in both absolute configurations by chemical and biocatalytic methods.

Since several phytopathogenic fungi have been reported to detoxify phytoalexins [12] producing less toxic degradation products than the parent compounds [13], we decided to study the biotransformation of 1-(4'-chlorophenyl)-1-cyclopropyl methanol (3) by $B$. cinerea as a part of the fungal detoxification mechanism. Previous studies of the detoxification of 1-(4'-chlorophenyl)-2phenylethanol (4) by $B$. cinerea and $C$. gloeosporioides suggest that it is not likely to persist in the environment for long periods postapplication [14].

\section{Experimental}

\subsection{General experimental procedures}

Optical rotations were determined with a Perkin-Elmer 241 polarimeter. IR spectra were recorded on a Mattson Genesis spectrophotometer, series FTIR. ${ }^{1} \mathrm{H}$ and ${ }^{13} \mathrm{C}$ NMR measurements were obtained on Varian Unity 400 and Varian Unity 600 NMR spectrometers with $\mathrm{SiMe}_{4}$ as the internal reference. Mass spectra were recorded on a GC-MS Thermoquest spectrometer (model: Voyager), and a VG Autospec-Q spectrometer. HPLC was performed with a Hitachi/Merck L-6270 apparatus equipped with a UV-VIS 
detector (L 6200) and a differential refractometer detector (RI71). TLC was performed on Merck Kiesegel $60 \mathrm{~F}_{254}, 0.2 \mathrm{~mm}$ thick. Silica gel (Merck) was used for column chromatography. Purification by means of HPLC was accomplished with a silica gel column (Hibar $60,7 \mathrm{~m}, 1 \mathrm{~cm}$ wide, $25 \mathrm{~cm}$ long). Chemicals were produced by Fluka or Aldrich. All solvents used were freshly distilled. Baker's yeast was obtained from a local store. The following enzymes were used in this work: Candida rugosa lipase (CRL, Sigma, Type VII, $950 \mathrm{U} / \mathrm{mg}$ ), Pseudomonas cepacia lipase (PSL, Amano Pharmaceuticals Co., Japan) and porcine pancreas lipase (PPL, Sigma, Type II).

\subsection{Chemical transformations}

\subsubsection{Synthesis of racemic substrates}

Compounds 4'-chlorophenyl cyclopropyl ketone (1) (2g, $0.012 \mathrm{~mol})$ and benzyl 4-chlorophenyl ketone (2) $(2 \mathrm{~g}, 0.008 \mathrm{~mol})$ were treated with $\mathrm{NaBH}_{4}(0.8 \mathrm{~g}, 0.02 \mathrm{~mol})$ in methylene chloride:methanol $1: 1(400 \mathrm{~mL})$ at room temperature stirring for $24 \mathrm{~h}$. Distillation under reduced pressure to eliminate the solvent led to a crude mixture that was neutralised with aqueous $\mathrm{HCl} 10 \%$ and extracted with ethyl acetate. The organic layer was dried over $\mathrm{Na}_{2} \mathrm{SO}_{4}$ and the solvent was eliminated by means of distillation under reduced pressure. The reduction mixture was chromatographed on a silica gel column eluting with hexane-ethyl acetate mixtures to give $( \pm)-1$ (4'-chlorophenyl)-1-cyclopropyl methanol (3) (1.98 g, 98\%) and ( \pm )-1-(4'-chlorophenyl)-2-phenylethanol (4) (1.85 g, 91\%), respectively. The ${ }^{1} \mathrm{H}$ NMR spectra of these products were in agreement with those found in the literature [15,16].

After purification, compounds $3(1.44 \mathrm{~g}, 0.006 \mathrm{~mol})$ or 4 $(1.5 \mathrm{~g}, 0.008 \mathrm{~mol})$ were dissolved in dry pyridine and acetic anhydride $(50 \mathrm{~mL})$ was added dropwise. The reaction mixtures were stirred for $20 \mathrm{~h}$. The solvent was then removed and the crude reaction product chromatographed to give $( \pm)-1$ (4'-chlorophenyl)-1-cyclopropyl methyl acetate (5) (94.1\%) and ( \pm )-1-(4-chlorophenyl)-2-phenylethyl acetate (6) [14] (93.2\%).

( \pm )-1-(4'-chlorophenyl)-1-cyclopropyl methyl acetate (5). Obtained as a colourless oil. IR $v_{\max }$ (film): 2925, 1738, 1615, 1371, 1090,$818 ;{ }^{1} \mathrm{H}$ NMR $\left(400 \mathrm{MHz}, \mathrm{CDCl}_{3}\right): \delta 0.36(\mathrm{~m}, 2 \mathrm{H}, \mathrm{H}-3), 0.54$ $(\mathrm{m}, 2 \mathrm{H}, \mathrm{H}-4), 1.25(\mathrm{~m}, 1 \mathrm{H}, \mathrm{H}-2), 2.09\left(\mathrm{~s}, 3 \mathrm{H},-\mathrm{COOCH}_{3}\right), 5.17(\mathrm{~d}, 2 \mathrm{H}$, $\left.J_{1-2}=8.7 \mathrm{~Hz}, \mathrm{H}-1\right), 7.31$ (bs, $\left.4 \mathrm{H}, \mathrm{Ar}-\mathrm{H}\right) ;{ }^{13} \mathrm{C}$ NMR $\left(100 \mathrm{MHz}, \mathrm{CDCl}_{3}\right)$ : $\delta 3.0(\mathrm{t}, \mathrm{C}-4), 4.1$ (t, C-3), 16.4 (d, C-2), $21.2\left(\mathrm{c},-\mathrm{COOCH}_{3}\right), 78.4(\mathrm{~d}$, C-1), 127.9 (d, C-2', C-6'), 128.5 (d, C-3', C-5'), 133.5 (s, C-4'), 138.8 (s, $\left.\mathrm{C}-1^{\prime}\right), 170.2(\mathrm{~s}, \mathrm{C}=0)$. MS ( $\left.\mathrm{m} / \mathrm{z}, \%\right): 226\left(\mathrm{M}^{+}+2,2\right), 224\left(\mathrm{M}^{+}, 5\right)$, $164\left(\mathrm{M}^{+}-60,71\right), 138$ (100), 77 (50).

Enantiomeric excesses were determined by means of HPLC analyses on a chiral column (Chiralcel OD, Daicel, Japan): $254 \mathrm{~nm}, 0.5 \mathrm{~mL} / \mathrm{min}$, hexane:isopropanol $(95: 5)(R)-3 t_{\mathrm{R}}=18.6 \mathrm{~min}$, $(S)-3 t_{R}=21.6 \mathrm{~min} ; 0.8 \mathrm{~mL} / \mathrm{min}$, hexane:isopropanol $(97: 3)(S)-4$ $t_{\mathrm{R}}=20.3 \mathrm{~min},(R)-4 t_{\mathrm{R}}=29 \mathrm{~min} ; 0.7 \mathrm{~mL} / \mathrm{min}$, hexane:isopropanol (99.5:0.5) (R)-5 $t_{\mathrm{R}}=9 \mathrm{~min},(S)-5 t_{\mathrm{R}}=14 \mathrm{~min}$; $0.7 \mathrm{~mL} / \mathrm{min}$, hexane:isopropanol (99.5:0.5) $(S)-6 t_{\mathrm{R}}=8 \mathrm{~min},(R)-6 t_{\mathrm{R}}=10 \mathrm{~min}$.

\subsubsection{Synthesis of enantiomeric alcohols}

2.2.2.1. (S)-(-)-1-(4'-chlorophenyl)-1-cyclopropylmethanol (S)-3. Under an argon atmosphere, an oven-dried Schlenk tube was charged with (S)-methyl oxazaborolidine $(0.086 \mathrm{mmol}, 86 \mu \mathrm{L}$ of $1 \mathrm{M}$ solution in toluene) [17]. The solvent was removed under high vacuum conditions ( $0.1 \mathrm{mbar}$ ) at room temperature and tetrahydrofuran (THF, $11 \mathrm{~mL}$ ) was added. Once the solution was cooled to $0^{\circ} \mathrm{C}$, it was treated with a borane-THF complex $(1.0 \mathrm{M}, 1.29 \mathrm{~mL})$ and stirred at room temperature for $2 \mathrm{~h}$. This reagent and a solution of 4'-chlorophenyl cyclopropyl ketone (1) $(155 \mathrm{mg}, 0.997 \mathrm{mmol})$ in THF $(10 \mathrm{~mL})$ were then added simultaneously from two syringes into an oven dried, round-bottomed flask at a temperature of $30^{\circ} \mathrm{C}$ over a period of $14 \mathrm{~h}$. After the reaction mixture was stirred for an additional $1 \mathrm{~h}$, water $(20 \mathrm{~mL})$ was added, the organic solvent was removed by means of rotary evaporation and the remaining aqueous phase was extracted with diethyl ether. The combined organic layers were then dried over magnesium sulphate. Removal of the solvent by means of rotary evaporation and subsequent filtration through a short silica gel column afforded $153.9 \mathrm{mg}$ (98.1\%) of the $(S)$-alcohol $\left([\alpha]_{\mathrm{D}}^{20}=-9.1^{\circ}\left(c 2.9\right.\right.$ in $\left.\left.\mathrm{CHCl}_{3}\right), 40.1 \% e e\right)$.

2.2.2.2. (R)-(+)-1-(4'-chlorophenyl)-1-cyclopropylmethanol (R)-3 and $(R)-(+)-1-\left(4^{\prime}-\right.$ chlorophenyl)-2-phenylethanol $(R)-4$. Under an argon atmosphere, an oven-dried Schlenk tube was charged with $(R)$-methyl oxazaborolidine $(0.086 \mathrm{mmol}, 100 \mu \mathrm{L}$ of $1 \mathrm{M}$ solution in toluene). The solvent was removed under high vacuum conditions $(0.1 \mathrm{mbar})$ at room temperature and tetrahydrofuran (THF, $11 \mathrm{~mL}$ ) was added. The solution was then cooled to $0{ }^{\circ} \mathrm{C}$, treated with a borane-THF complex $(1.0 \mathrm{M}, 1.49 \mathrm{~mL})$ and stirred at room temperature for $2 \mathrm{~h}$. This reagent and a solution of $4^{\prime}$-chlorophenyl cyclopropyl ketone (1) $(180 \mathrm{mg}, 0.996 \mathrm{mmol})$ or benzyl $4^{\prime}$ chlorophenyl ketone (2) (230 mg, $1.0 \mathrm{mmol})$, respectively, in THF $(10 \mathrm{~mL})$, were then added simultaneously from two syringes into an oven dried, round-bottomed flask at a temperature of $30^{\circ} \mathrm{C}$ over a period of $16 \mathrm{~h}$. The work-up procedure was essentially the same as that described above affording $175.3 \mathrm{mg}(96.3 \%)$ of $(R)-3$ $\left([\alpha]_{\mathrm{D}}^{20}=+9.4^{\circ}\left(\mathrm{c} 2.1 \mathrm{in} \mathrm{CHCl}_{3}\right), 45.2 \%\right.$ ee $)$ and $227 \mathrm{mg}(98 \%)$ of $(R)-4$ $\left([\alpha]_{\mathrm{D}}^{20}=+23.3^{\circ}\left(\right.\right.$ c 1.2 in $\left.\mathrm{CHCl}_{3}\right),>99 \%$ ee $)$, respectively.

\subsubsection{Treatment of 1-(4'-chlorophenyl)-1-cyclopropylmethanol} (3) in Czapek-Dox medium

The compound $( \pm)-1$-(4'-chlorophenyl)-1cyclopropylmethanol (3) $(10 \mathrm{mg}, \quad 0.055 \mathrm{mmol})$ in $100 \mathrm{~mL}$ of Czapek-Dox medium at $\mathrm{pH} 4$ was stirred at room temperature for $120 \mathrm{~h}$ without the fungus $B$. cinerea. No reaction products were obtained.

\subsection{General procedure for the baker's yeast transformation}

A mixture composed of baker's yeast (250 g), D-glucose (100 g), and tap water $(1 \mathrm{~L})$ was stirred in a $2 \mathrm{~L}$ beaker at $50^{\circ} \mathrm{C}$ for $30 \mathrm{~min}$. The substrate $(2 \mathrm{~g})$, dissolved in the minimum amount of ethanol, was then added dropwise. At the end of the reaction period, $1 \mathrm{~L}$ of ethyl acetate was added and the crude reaction mixture filtered through a large Büchner funnel on a Celite pad, which was later washed with the same solvent. The aqueous phase was extracted twice with $0.5 \mathrm{~L}$ of ethyl acetate, the organic phase dried over $\mathrm{Na}_{2} \mathrm{SO}_{4}$, and the solvent then evaporated under reduced pressure to dryness. The residue obtained was purified by means of column chromatography.

\subsubsection{Baker's yeast transformation in the presence of several additives}

A mixture of baker's yeast $(250 \mathrm{~g})$, water $(1 \mathrm{~L})$, and D-glucose $(100 \mathrm{~g}, 0.505 \mathrm{~mol})$ was stirred at $50^{\circ} \mathrm{C}$ for $30 \mathrm{~min}$. The substrate $(2 \mathrm{~g})$ was dissolved in $8 \mathrm{~mL}$ of allyl alcohol ( $67 \mathrm{mmol}$ ) and $12 \mathrm{~mL}$ of hexane $(1.2 \%)$ and was then added dropwise to the mixture [18]. The reaction was then stirred for a further period of time. The work-up procedure was essentially the same as that described above. The results are shown in Table 1.

\subsection{Lipase-mediated reactions}

\subsubsection{Lipase-mediated acetylations}

A mixture of racemic alcohol 3 or $\mathbf{4}(50 \mathrm{mg})$, lipase $(50 \mathrm{mg})$, and vinyl acetate in tert-butylmethyl ether (TBME) $(2 \mathrm{~mL}$ ) was stirred at room temperature. The residue obtained upon evaporation of the filtered reaction mixture was chromatographed on a silica gel col- 
Table 1

Results of baker's yeast-mediated reduction.

\begin{tabular}{|c|c|c|c|c|c|}
\hline Substrate & Allyl alcohol (mM) & Hexane (\%) & Conversion ${ }^{\mathrm{a}} \%$ ) & $e e(\%)$ & Time $(\mathrm{h}$ \\
\hline \multirow{2}{*}{1} & - & - & 5.0 & 27 & 72 \\
\hline & 67 & 1.2 & 12.0 & 96 & 96 \\
\hline \multirow[t]{4}{*}{2} & - & - & 1.0 & 50 & 72 \\
\hline & - & - & 15.3 & 67 & 96 \\
\hline & 67 & 1.2 & 2.0 & 99 & 168 \\
\hline & 67 & 1.2 & 3.7 & 94 & 240 \\
\hline
\end{tabular}

a $\%$ of product in the recovered material.

Table 2

Results of lipase-mediated acetylation.

\begin{tabular}{|c|c|c|c|c|c|c|c|c|c|c|}
\hline Substrate & Enzyme & Vinyl acetate $(\mathrm{mmol})$ & Temp. $\left({ }^{\circ} \mathrm{C}\right)$ & Time $(\mathrm{h})$ & Yield $_{\mathrm{p}}(\%)^{\mathrm{a}}$ & $e e_{\mathrm{p}}(\%)$ & Yield $_{s}(\%)$ & $e e_{s}(\%)$ & Conversion (\%) & E \\
\hline \multirow{4}{*}{3} & PSL & 2.3 & RT & 72 & 18.0 & 97 & 78.4 & 88 & 47.6 & 190 \\
\hline & PSL & 0.23 & RT & 47.5 & 1.0 & 74 & 85.6 & 78 & 51.3 & 16 \\
\hline & PSL & 10 & RT & 240 & 29.0 & 90 & 84.0 & 18 & 16.5 & 24 \\
\hline & PPL & 10 & RT & 240 & 10.0 & $>99$ & 93.0 & 7 & 6.6 & $>200$ \\
\hline \multirow{4}{*}{4} & PSL & 0.23 & RT & 96 & 2.7 & 54 & 87.3 & 24 & 31.0 & 4 \\
\hline & PSL & 0.23 & RT & 168 & 15.3 & 67 & 80.0 & 42 & 38.5 & 8 \\
\hline & PSL & 10 & 48 & 264 & 10.0 & 70 & 94.0 & 6 & 6.0 & 6 \\
\hline & PPL & 10 & 40 & 264 & 10.0 & 97 & 94.0 & 6 & 6.0 & 73 \\
\hline
\end{tabular}

a Yield $100 \%$ at $50 \%$ conversion after hydrolysis of the acetate derivative.

umn and eluted with hexane:ethyl acetate (95:5). The first eluted fractions provided the acetate derivatives $(R)-\mathbf{5}\left([\alpha]_{\mathrm{D}}^{20}=+1(c 1.1\right.$ in $\left.\left.\mathrm{CHCl}_{3}\right),>99 \% e e\right)$ and $(R)-\mathbf{6}\left([\alpha]_{\mathrm{D}}^{20}=+5\left(c 1.7\right.\right.$ in $\left.\left.\mathrm{CHCl}_{3}\right), 97 \% e e\right)$ while the last afforded the unreacted starting material. Detailed results of the enzyme-mediated acetylations are reported in Table 2.

Treatment of acetate derivatives $(R)-\mathbf{5}(300 \mathrm{mg}, 1.32 \mathrm{mmol})$ and $(R)-6$ (375 mg, $1.4 \mathrm{mmol}$ ), respectively, with $\mathrm{KOH}(100 \mathrm{mg}$, $2 \mathrm{mmol}$ ) in methanol solution at room temperature for $2 \mathrm{~h}$ afforded $239.4 \mathrm{mg}(97.8 \%)$ of the compound $(R)-(+)-1-\left(4^{\prime}\right.$-chlorophenyl)1-cyclopropyl methanol $(R)-3\left([\alpha]_{\mathrm{D}}^{20}=+21^{\circ}\left(\right.\right.$ c 2.7 in $\left.\mathrm{CHCl}_{3}\right)$, $>99 \% e e)$ and $321.2 \mathrm{mg}(98.8 \%)$ of $(R)-(+)-1-\left(4^{\prime}\right.$-chlorophenyl)2-phenylethanol $(R)-4\left([\alpha]_{\mathrm{D}}^{20}=+22^{\circ}\left(c \quad 1.6\right.\right.$ in $\left.\mathrm{CHCl}_{3}\right), 97 \%$ ee $)$, respectively.

\subsubsection{Lipase-mediated hydrolysis}

Lipase (90 mg of PSL, $60 \mathrm{mg}$ of PPL or CRL) was added to a mixture of racemic acetates 5 or $\mathbf{6}(0.075 \mathrm{mmol})$ in $1.5 \mathrm{~mL}$ of solvent (mixture of 1,4-dioxane and buffer $\mathrm{KH}_{2} \mathrm{PO}_{4}: \mathrm{KOH} 0.1 \mathrm{M} \mathrm{pH}$ 7 ). The solution was stirred at room temperature. The residue obtained upon evaporation of the filtered reaction mixture was chromatographed on a silica gel column and eluted with hexane:ethyl acetate (95:5). The first eluted fractions provided the unreacted starting material and the last eluted fractions afforded the alcohol derivatives $(R)-(+)-1-\left(4^{\prime}\right.$-chlorophenyl)-1-cyclopropyl methanol $(R)-3\left([\alpha]_{\mathrm{D}}^{20}=+20^{\circ}\left(c 1.3\right.\right.$ in $\left.\mathrm{CHCl}_{3}\right), 98 \%$ ee $)$ and $(R)-(+)-$ $1-\left(4^{\prime}\right.$-chlorophenyl)-2-phenylethanol $(R)-4\left([\alpha]_{\mathrm{D}}^{20}=+4.8^{\circ}\right.$ (c 1.0 in $\left.\left.\mathrm{CHCl}_{3}\right), 21.3 \% e e\right)$, respectively. Detailed results are reported in Table 3.

\subsection{Microorganism culture and antifungal assays}

The culture of $B$. cinerea employed in this work, B. cinerea UCA992, was obtained from grapes from the Domecq vineyard, Jerez de la Frontera, Cádiz, Spain. This culture is deposited in the Mycological Herbarium Collection (Universidad de Cádiz).

Antifungal activity was determined by means of a conidial germination assay. The test compound was dissolved in the minimum amount of ethanol, and water was then added to give a final compound concentration of $10-150 \mathrm{mg} \mathrm{L}^{-1}$. Two microlitres of a conidial suspension in water containing about $5 \times 10^{4}$ conidia $/ \mathrm{mL}$ of the $B$. cinerea strain were added to a solution of the test compound $(15 \mu \mathrm{L})$ and PDB (potato dextrose broth) medium $(2 \mu \mathrm{L})$ on ELISA plates. The final ethanol concentration was identical in control and treated cultures. Three replicates were made per compound and the viability of conidia was estimated by measuring germination just after incubation at $25^{\circ} \mathrm{C}$ for $24 \mathrm{~h}$.

\subsection{Biotransformation of ( \pm )-1-(4'-chlorophenyl)-1-cyclopropyl methanol (3) by B. cinerea UCA992}

B. cinerea UCA992 was grown as a surface culture in Roux bottles at $25^{\circ} \mathrm{C}$ on a Czapek-Dox medium ( $150 \mathrm{~mL}$ per bottle) for 2 days. Substrate 3 was dissolved in ethanol and then distributed over 17 Roux bottles (100 ppm per bottle). Fermentation continued for a further period of 5 days. The mycelium was filtered and washed with brine and ethyl acetate. The broth was extracted three times with ethyl acetate and the extract dried over anhydrous sodium sulphate. The solvent was then evaporated and the residue was chromatographed first on a silica gel

Table 3

Results of lipase-mediated hydrolysis.

\begin{tabular}{|c|c|c|c|c|c|c|c|c|c|}
\hline Substrate & Enzyme & Buffer (\%) & Time (h) & Yield $_{p}(\%)$ & $e e_{\mathrm{p}}(\%)$ & Yield $_{s}(\%)$ & $e e_{\mathrm{s}}(\%)$ & Conv. (\%) & $E$ \\
\hline \multirow{7}{*}{5} & PPL & 83 & 192 & 38.0 & 96 & 65.0 & 88 & 47.7 & 142 \\
\hline & PSL & 83 & 192 & 66.0 & 73 & 28.0 & 70 & 49.0 & 13 \\
\hline & CRL & 67 & 480 & 76.0 & 71 & 21.0 & 40 & 36.0 & 9 \\
\hline & CRL & 67 & 240 & 85.5 & 98 & 13.0 & 87 & 47.0 & $>200$ \\
\hline & CRL & 20 & 288 & 42.0 & 38 & 40.0 & 10 & 20.6 & 2 \\
\hline & PPL & 20 & 288 & 17.0 & 36 & 71.0 & 23 & 39.0 & 3 \\
\hline & PSL & 20 & 288 & 46.7 & 47 & 40.0 & 33 & 41.0 & 4 \\
\hline 6 & CRL & 20 & 360 & 10.0 & 21.3 & 75.6 & 12 & 36.8 & 2 \\
\hline
\end{tabular}

Conv., conversion. 
column and then with HPLC with an increasing gradient of ethyl acetate to petroleum ether. The following compounds were isolated: recovered $( \pm)-1$-(4'-chlorophenyl)-1-cyclopropylmethanol (3) $(207.5 \mathrm{mg}), 4^{\prime}$-chlorophenyl cyclopropyl ketone (1) (2 mg) and di( $4^{\prime}$-chlorophenyl cyclopropyl methyl)ether (7) (4 mg).

$\mathrm{Di}\left(4^{\prime}\right.$-chlorophenyl cyclopropyl methyl)ether (7). Obtained as a colourless oil, anti/syn $50: 50$ as determined by ${ }^{1} \mathrm{H}$ NMR spectroscopy. IR $v_{\max }$ (film): 2923, 1490, 1062, 817. MS (m/z, \%): 346 $\left(\mathrm{M}^{+},>0.1\right), 183(2), 181$ (5), 167 (32), 165 (100), 132 (2), 130 (35). $m / z$ HRMS (EI, $70 \mathrm{eV}$ ) calcd. for $\mathrm{C}_{20} \mathrm{H}_{20} \mathrm{OCl}_{2}: 346.08912$ [M] $]^{+}$; found: 346.0913. syn-isomer: ${ }^{1} \mathrm{H}$ NMR $\left(400 \mathrm{MHz}, \mathrm{CDCl}_{3}\right): \delta 0.16(\mathrm{~m}, 2 \mathrm{H}, \mathrm{H}-$ 3), $0.42(\mathrm{~m}, 4 \mathrm{H}, \mathrm{H}-3, \mathrm{H}-4), 0.66(\mathrm{~m}, 2 \mathrm{H}, \mathrm{H}-4), 1.09(\mathrm{~m}, 2 \mathrm{H}, \mathrm{H}-2), 3.86$ (d, $2 \mathrm{H}, J=7.9 \mathrm{~Hz}, \mathrm{H}-1$ ), 7.19 (d, $4 \mathrm{H}, J=8.3 \mathrm{~Hz}, \mathrm{H}-2^{\prime}, \mathrm{H}-6^{\prime}$ ), 7.25 (d, $\left.4 \mathrm{H}, J=8.3 \mathrm{~Hz}, \mathrm{H}-3^{\prime}, \mathrm{H}-5^{\prime}\right) .{ }^{13} \mathrm{C}$ NMR $\left(100 \mathrm{MHz}, \mathrm{CDCl}_{3}\right): \delta 1.6$ (t, C-3), 5.0 (t, C-4), 17.3 (d, C-2), 81.7 (d, C-1), 128.2 (d, C-2', C-6'), 128.4 (d, C-3', C-5'), 133.0 (s, C-1'), 141.1 (s, C-4'). anti-isomer: ${ }^{1} \mathrm{H}$ NMR $\left(400 \mathrm{MHz}, \mathrm{CDCl}_{3}\right): \delta 0.08(\mathrm{~m}, 2 \mathrm{H}, \mathrm{H}-3), 0.21(\mathrm{~m}, 2 \mathrm{H}, \mathrm{H}-4), 0.36(\mathrm{~m}$, $2 \mathrm{H}, \mathrm{H}-3), 0.60$ ( $\mathrm{m}, 2 \mathrm{H}, \mathrm{H}-4), 1.13(\mathrm{~m}, 2 \mathrm{H}, \mathrm{H}-2), 3.25$ (d, $2 \mathrm{H}, J=8.2 \mathrm{~Hz}$, $\mathrm{H}-1$ ), 7.17 (d, 4H, J=8.3 Hz, H-2', H-6'), 7.31 (d, 4H, J= 8.3 Hz, H-3', $\left.\mathrm{H}-5^{\prime}\right) .{ }^{13} \mathrm{C} \mathrm{NMR}\left(100 \mathrm{MHz}, \mathrm{CDCl}_{3}\right): \delta 2.5(\mathrm{t}, \mathrm{C}-3), 4.6(\mathrm{t}, \mathrm{C}-4), 18.3(\mathrm{~d}$, C-2), 82.2 (d, C-1), 128.3 (d, C-2', C-6'), 128.6 (d, C-3', C-5'), 133.3 (s, C- $\left.1^{\prime}\right), 140.4\left(\mathrm{~s}, \mathrm{C}-4^{\prime}\right)$. HPLC (Chiralcel OD, Daicel, Japan, hexane/IPA 9.8:0.2, $0.6 \mathrm{~mL} / \mathrm{min}$ ): anti- $t_{\mathrm{R}} 7.3 \mathrm{~min}$ (major) and $9.7 \mathrm{~min}$ (minor); syn- $t_{\mathrm{R}} 6.7 \mathrm{~min}$ (minor) and $7.2 \mathrm{~min}$ (major).

\section{Results and discussion}

\subsection{Chemical transformations}

The chemical preparation of the (S)-enantiomer of 1-(4'chlorophenyl)-2-phenylethanol( $S$ )-4 was previously reported with excellent yield and enantiomeric excess [14]. Thus, in order to obtain $(R)-1-\left(4^{\prime}\right.$-chlorophenyl)-2-phenylethanol $(R)-4$ and both enantiomers of 1-(4'-chlorophenyl)-1-cyclopropyl methanol (3) [15], we employed the same chemical experimental procedure consisting of treatment of $4^{\prime}$-chlorophenyl cyclopropyl ketone $(\mathbf{1})$ or benzyl 4'-chlorophenyl ketone (2) with $\mathrm{BH}_{3}-\mathrm{THF}$ and $(R)$ - or $(S)$ methyl oxazaborolidine [17]. Alcohol $(R)-4$ was obtained with $>99 \%$ $e e$ and $98 \%$ yield but results in obtaining $(R)$ - or $(S)$-3 were moderate (45.2\% ee for $(R)-3$ and $40.1 \%$ ee for $(S)-3)$. Enantiomeric excesses were determined by HPLC analysis using a Chiralcel OD column.

\subsection{Biocatalytic transformations}

\subsubsection{Baker's yeast reduction}

Based on the well known ability of baker's yeast fermentation to reductively transform a variety of ketones into optically active alcohols with (S)-configuration (Prelog specificity family) [18], we decided to use a baker's yeast-mediated approach to enantiopurify $(S)-(-)-1-\left(4^{\prime}\right.$-chlorophenyl)-1-cyclopropyl methanol $(S)-3$ and (S)-(-)-1-(4'-chlorophenyl)-2-phenylethanol (S)-4, using the corresponding ketones $\mathbf{1}$ and $\mathbf{2}$ as substrates. The results are shown in Table 1.

A major limitation of this methodology is the difficulty in extracting the product from the fermentation broth; consequently, often only moderate yields of products are obtained, presumably due to absorption of the starting material and/or product within the larger quantity of yeast cells $[19,20]$.

As shown in Table 1, after the incubation of ketones $\mathbf{1}$ and $\mathbf{2}$ in fermenting baker's yeast following the conventional procedure (see Section 2), a single transformation product was isolated, (S)-(-)1-(4'-chlorophenyl)-1-cyclopropyl methanol $(S)$-3 (5\% conversion, $[\alpha]_{\mathrm{D}}^{20}=-5.7^{\circ}\left(\right.$ c 1.9 in $\left.\mathrm{CHCl}_{3}\right), 27 \%$ ee $)$ and $(S)-1-\left(4^{\prime}\right.$-chlorophenyl $)-$ 2-phenylethanol $(S)-4\left(15.3 \%\right.$ conversion, $[\alpha]_{\mathrm{D}}^{20}=-15.4^{\circ}$ (c 1.5 in $\mathrm{CHCl}_{3}$ ), 67\% ee), respectively (Scheme 1 ). In order to improve

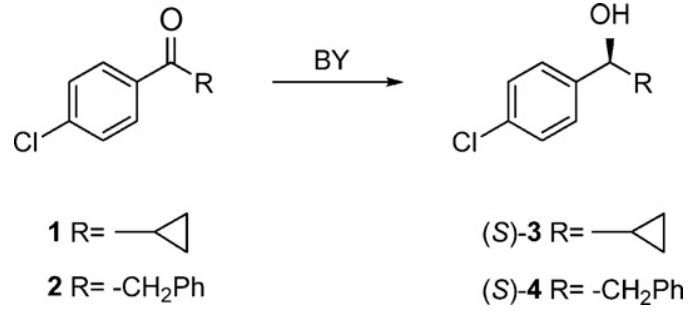

Scheme 1.

the transformation and the ee, we therefore tried to inhibit the reducing enzymes selectively by adding inhibitors such as allyl alcohol and a small amount of organic solvent [21] to dissolve the substrate (see Table 1). The addition of allyl alcohol and hexane improved the ee of both alcohols significantly, but the conversion itself was diminished for (S)-4: (S)-(-)-1-(4'-chlorophenyl)-1cyclopropyl methanol $(S)-3$ (12\% conversion, $[\alpha]_{D}^{20}=-20.1^{\circ}$ (c 0.9 in $\left.\mathrm{CHCl}_{3}\right), 96 \%$ ee) and (S)-1-(4'-chlorophenyl)-2-phenylethanol $(S)-4\left(2 \%\right.$ conversion, $[\alpha]_{D}^{20}=-22^{\circ}\left(c 1.8\right.$ in $\left.\mathrm{CHCl}_{3}\right), 99 \%$ ee $)$, respectively. The spectroscopic data of these products corresponded to those found in the literature $[15,16]$.

\subsubsection{Lipase-mediated transformations}

In order to study new methods for the preparation of the enantiomerically pure alcohols $\mathbf{3}$ and $\mathbf{4}$, we focused on the kinetic resolution of the racemic secondary alcohols and acetates, obtained as described in the experimental section. Lipases are versatile biocatalysts acting with high efficiency in acylation or hydrolysis $[11,22]$.

3.2.2.1. Lipase-mediated acetylations. The starting material $\mathbf{3}$ or $\mathbf{4}$ was added to different media with vinyl acetate as an acyl donor and tert-butyl methyl ether as the organic solvent and three different lipases: lipase PS (from Pseudomonas cepacia), PPL (porcine pancreas lipase) and CRL (Candida rugosa lipase). The lipases investigated converted the $R$ enantiomers of $\mathbf{3}$ and $\mathbf{4}$ in accordance with Kazlauskas' empirical rule for secondary alcohols (Scheme 2) [23]. The results are summarised in Table 2 .

The lipase PPL appeared to be more efficient for the enzymatic acetylation of these substrates affording the highest enantioselectivities. However, this enhanced selectivity was accompanied by a moderate reaction rate. CRL was rejected as a possible mediator due to the low selectivity and slow conversions observed when it was used. Lipase PSL showed high enantioselectivity and yield for compound 3 but low selectivity for alcohol 4 .

In an attempt to increase the low conversion rate and enantioselectivity showed for substrate $\mathbf{4}$ with all the lipases at room temperature, we also studied the effect of temperature on reaction conditions. We found that transesterification at the optimal temperature of each enzyme increased both parameters, conversion and enantiomeric excesses. This indicates that temperature may accelerate the kinetics of the enzyme. Different reaction times and vinyl acetate concentrations were also tested (see Table 2).
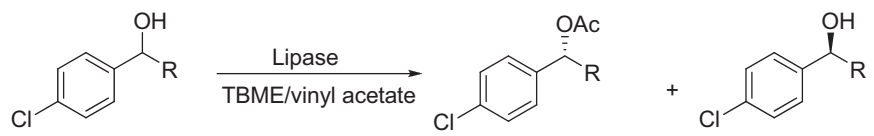

$3 \mathrm{R}=\longrightarrow$

$4 \mathrm{R}=-\mathrm{CH}_{2} \mathrm{Ph}$

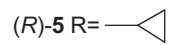

(S)-3 $\mathrm{R}=\longrightarrow$

$(R)-6 \mathrm{R}=-\mathrm{CH}_{2} \mathrm{Ph}$

(S) $-4 \mathrm{R}=-\mathrm{CH}_{2} \mathrm{Ph}$ 
<smiles>[R]C(O[C@@H](C)O[Na])c1ccc(Cl)cc1</smiles><smiles>[R]C(O)c1ccc(Cl)cc1</smiles>

$$
\begin{aligned}
& 5 \mathrm{R}=\square \\
& 6 \mathrm{R}=-\mathrm{CH}_{2} \mathrm{Ph}
\end{aligned}
$$

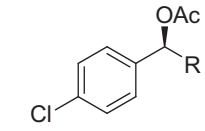

$(S)-5 \mathrm{R}=\longrightarrow$

(S)-6 R= - $\mathrm{CH}_{2} \mathrm{Ph}$<smiles>OC(c1ccc(Cl)cc1)C1CC1</smiles>

3<smiles>O=C(c1ccc(Cl)cc1)C1CC1</smiles>

1

Scheme 4.

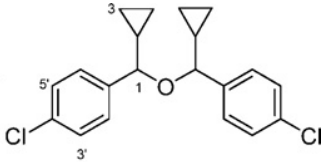

7

Scheme 3.

The best results for $\mathbf{3}$ and $\mathbf{4}$ were obtained with lipase PPL giving acetate derivatives with yields of $10 \%$ and $>99 \%$ and $97 \%$ ee, respectively, using $10 \mathrm{mmol}$ of vinyl acetate as the acyl donor.

After hydrolysis of the acetate derivatives with potassium hydroxide in methanol, the enantiopure alcohols were identified as $(R)-(+)-1-\left(4^{\prime}\right.$-chlorophenyl)-1-cyclopropyl methanol $(R)-3\left([\alpha]_{\mathrm{D}}^{20}=\right.$ $+21^{\circ}$ (c 2.7 in $\left.\mathrm{CHCl}_{3}\right),>99 \%$ ee $)$ and $(R)-(+)-1-\left(4^{\prime}\right.$-chlorophenyl)2-phenylethanol $(R)-4\left([\alpha]_{\mathrm{D}}^{20}=+22^{\circ}\left(\right.\right.$ c 1.6 in $\left.\mathrm{CHCl}_{3}\right), 97 \%$ ee $)$, respectively. In general, the results obtained for alcohol $(R)-\mathbf{4}$ are moderate owing to its low solubility which decreases the transformation.

3.2.2.2. Lipase-mediated hydrolysis. Herein we report on the enzyme mediated enantioselective hydrolysis of acetates 1(4'-chlorophenyl)-1-cyclopropyl methyl acetate (5) and 1-(4chlorophenyl)-2-phenylethyl acetate (6) [14].

The racemic acetate derivatives were prepared by adding the corresponding alcohols to a solution of acetic anhydride in dichloromethane:methanol (1:1). The acetates were then transformed by lipases dissolved in a mixture of 1,4-dioxane and different concentrations of buffer solution (see Scheme 3). The results of the enzymatic hydrolysis are summarized in Table 3.

The 1-(4'-chlorophenyl)-1-cyclopropyl methyl acetate (5) was transformed to $(R)-(+)-1-\left(4^{\prime}\right.$-chlorophenyl)-1-cyclopropyl methanol $(R)-3$ with a high ee of $98 \%$ with a conversion of $47 \%$ using CRL as catalyst and $67 \%$ of buffer. For 1-(4'chlorophenyl)-2-phenyethanol (4) the enantiomer obtained was $(R)-(+)-1-\left(4^{\prime}\right.$-chlorophenyl)-2-phenyethanol $(R)-4$ in only one case, using CRL as biocatalyst with $20 \%$ aqueous buffer. The low solubility of this compound makes it very difficult for the reaction to take place with moderate amounts of water (necessary for the hydrolysis reaction). Thus, the final product $(R)-\mathbf{4}$ with high enantiomeric excess could not be obtained by means of this methodology.

\section{Detoxification by B. cinerea}

The biotransformation of the fungistatic agent 1-(4'chlorophenyl)-2-phenyethanol (4) by the phytopathogen $B$. cinerea has been studied in a previous report [14]. In incorporation experiments of 4 at a concentration of $150 \mathrm{ppm}$, B. cinerea was unable to detoxify this compound. When biotransformation was carried out at a lower concentration, the ketone derivative was obtained as the only product, benzyl 4'-chlorophenyl ketone (2), which showed less antifungal activity than the corresponding alcohol 4 against the fungus $B$. cinerea [10], suggesting that the fungus has its own detoxification mechanism.

Thus, in order to investigate the detoxification mechanisms for antifungal compound 3, the biotransformation of that alcohol by $B$. cinerea UCA992 was studied.

\subsection{Detoxification of ( \pm )-1-(4'-chlorophenyl)-1-cyclopropyl methanol (3) by B. cinerea UCA992}

Biotransformation was carried out on surface cultures using Roux bottles for five days, after which the mycelium was filtered,

extracted with ethyl acetate and the extract dried over anhydrous sodium sulphate. In addition to the starting material (see Scheme 4), the purification of the organic dry extract afforded two compounds: $4^{\prime}$-chlorophenyl cyclopropyl ketone (1), and compound 7, a mixture of diastereoisomers 50:50 of the corresponding dimer of the biotransformation starting material which could be separated by HPLC giving syn-7 (>99\% ee) and anti-7 (30\% ee). The presence of these compounds as biotransformation products shows the interesting enzymatic potential of the fungus B. cinerea UCA992 as a biocatalyst.

As mentioned above, apart from the ketone 1, the new compound $\mathbf{7}$ was isolated from the biotransformation. Many of the signals in their ${ }^{1} \mathrm{H}$ and ${ }^{13} \mathrm{C}$ NMR spectra were similar to those of 1-(4'-chlorophenyl)-1-cyclopropylmethanol (3). However, the signal corresponding to the hydroxyl group on C-1 was absent while the signal assigned to $\mathrm{H}-1$ was more deshielded, indicating that the hydroxy group of $\mathbf{3}$ had been etherificated with another molecule of the alcohol. In addition, the HRMS of the compound confirmed the structure of the new product as di(4'chlorophenyl cyclopropyl methyl)ether (7). To confirm that this compound was a biotransformation product and not a condensation product from the chemical reaction between two molecules of the starting material of the biotransformation, $\mathbf{3}$, we treated 1(4'-chlorophenyl)-1-cyclopropylmethanol (3) in the culture broth under the same conditions as those of the biotransformation, but without the fungus. No condensation compound was obtained.

The antifungal activity of the biotransformation products against the fungus $B$. cinerea was studied and proved to be less active than the alcohol used as substrate (for product 1 [10]) or completely inactive (compound 7 ). This fact confirms the existence of a detoxification mechanism by the phytopathogen.

\section{Conclusions}

The studies described above have demonstrated the potential of several methods, biocatalytic and chemical, to obtain enantiomerically pure forms of 1-(4'-chlorophenyl)-1-cyclopropyl methanol(3) and 1-(4'-chlorophenyl)-2-phenylethanol (4), which had already proven to be highly active against $B$. cinerea [10].

The best selectivity-yield relationship for the reduction of benzyl 4'-chlorophenyl ketone (2) was observed after treatment with oxazaborolidine [17], yielding compounds $(R)-\mathbf{4}$ and $(S)-4$ [14], with $>99 \%$ ee and $98 \%$ yield. However, results for ketone 1 were only moderate using this methodology.

We were thus able to obtain enantiomerically pure alcohols of 1-(4'-chlorophenyl)-1-cyclopropyl methanol (3) by means of biocatalytic methods. The best result for the preparation of $(S)-3$ (96\% ee) was observed after fermentation of 4'-chlorophenyl cyclopropyl ketone (1) with baker's yeast cells in the presence of allyl alcohol and hexane, while the best $R$ selectivity-yield relationship for compound 3 was after lipase-mediated hydrolysis of $1-\left(4^{\prime}-\right.$ chlorophenyl)-1-cyclopropyl methyl acetate (5) to give $(R)-\mathbf{3}$ with $98 \%$ ee.

Compounds $(R)$ - and $(S)-1-\left(4^{\prime}\right.$-chlorophenyl)-2-phenylethanol $(R)$ - and $(S)$-4 were also prepared by enzymatic methods with excellent enantioselectivity results. Thus, (S)-4 was obtained with $99 \%$ $e e$ by means of baker's yeast reduction in the presence of addi- 
tives while the best result for $(R)-\mathbf{4}(97 \%$ ee) was observed after lipase-mediated acetylation with PPL followed the hydrolysis of the acetate.

Based on previous results pointing to the high antifungal activity of enantiopure alcohols 3 and 4 [10] against the phytopathogen $B$. cinerea, and the detoxification mechanism exhibited by 4 [14], we also carried out the biotransformation of 1-(4'-chlorophenyl)1-cyclopropyl methanol (3) by the fungus. Biotransformation products have been shown to be less toxic to fungal growth than 3, confirming the existence of a detoxification mechanism by the phytopathogen. The main detoxification reaction involved oxidation of the starting material. It is also interesting to note the isolation of a new dimer compound of ( \pm )-1-(4'-chlorophenyl)-1cyclopropylmethanol (3) as a detoxification product by $B$. cinerea UCA992.

\section{Acknowledgements}

This work was supported by grants from MICINN (AGL200913359-C02-01) and from Junta de Andalucía (P07-FQM-02689).

\section{References}

[1] Y. Elad, B. Williamson, P. Tudzynsky, N. Delen, Botrytis: Biology, Pathology and Control, Kluwer Academic Publishers, Dordrecht, The Netherlands, 2004.

[2] I.G. Collado, J. Aleu, R. Hernández-Galán, R. Durán-Patrón, Curr. Org. Chem. 4 (2000) 1261-1286.

[3] L.G. Copping, H.G. Hewitt, Chemistry and Mode of Action of Crop Protection Agents, The Royal Society of Chemistry, London, U.K., 1998.

[4] J. Aleu, R. Hernández-Galán, J.R. Hanson, P.B. Hitchcock, I.G. Collado, J. Chem. Soc. Perkin Trans. 1 (1999) 727-730.

[5] A.J. Bustillo, J. Aleu, R. Hernández-Galán, I.G. Collado, J. Mol. Catal. B: Enzym. 21 (2003) 267-271.

[6] J. Aleu, J.R. Hanson, R. Hernández-Galán, I.G. Collado, J. Nat. Prod. 62 (1999) 437-440.

[7] J. Aleu, R. Hernández-Galán, I.G. Collado, J. Mol. Catal. B: Enzym. 16 (2002) 249-253.

[8] T. Kokubun, J.B. Harborne, J. Eagles, Phytochemistry 35 (1994) 331-333.

[9] F. Echeverri, F. Torres, W. Quiñones, G. Cardona, R. Archbold, J. Roldán, I. Brito, J.G. Luis, E.H. Lahlou, Phytochemistry 44 (1997) 255-256.

[10] L. Saiz-Urra, A.J. Bustillo Pérez, M. Cruz-Monteagudo, C. Pinedo-Rivilla, J. Aleu, R. Hernández-Galán, I.G. Collado, J. Agric. Food Chem. 57 (2009) 4838-4843.

[11] T. Hudlicky, J.W. Reed, Chem. Soc. Rev. 38 (2009) 3117-3132.

[12] R. Pezet, V. Pont, K. Hoang-Van, Physiol. Mol. Plant Pathol. 39 (1991) 441-450.

[13] A.E. Osbourn, Fungal Genet. Biol. 26 (1999) 163-168.

[14] A.J. Bustillo, C.M. García-Pajón, J. Aleu, R. Hernández-Galán, I.G. Collado, Tetrahedron: Asymmetry 14 (2003) 3755-3760.

[15] J.P. McCormick, A.S. Fitterman, D.L. Barton, J. Org. Chem. 46 (1981) 4708-4712.

[16] S.W. Li, Z.L. Zhou, Y.Z. Huang, L.L. Shi, J. Chem. Soc. Perkin Trans. 1 (1991) 1099-1100.

[17] E.J. Corey, C.J. Helal, Angew. Chem. Int. Ed. 37 (1998) 1986-2012.

[18] A.J. Bustillo, J. Aleu, R. Hernández-Galán, I.G. Collado, Tetrahedron: Asymmetry 13 (2002) 1681-1686.

[19] J. Aleu, G. Fronza, C. Fuganti, V. Perozzo, S. Serra, Tetrahedron: Asymmetry 9 (1998) 1589-1596.

[20] C. Pinedo-Rivilla, J. Aleu, M. Grande Benito, I.G. Collado, Org. Biomol. Chem. 8 (2010) 3784-3789.

[21] J.-N. Cui, T. Ema, T. Sakai, M. Utaka, Tetrahedron: Asymmetry 9 (1998) 2681-2692.

[22] G. De Gonzalo, R. Brieva, V.M. Sánchez, M. Bayod, V. Gotor, J. Org. Chem. 66 (2001) 8947-8953.

[23] R.J. Kazlauskas, A. Weissfloch, A.T. Rappaport, L.A. Cuccia, J. Org. Chem. 56 (1991) 2656-2665.

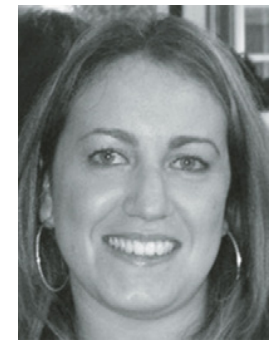

fungicides.
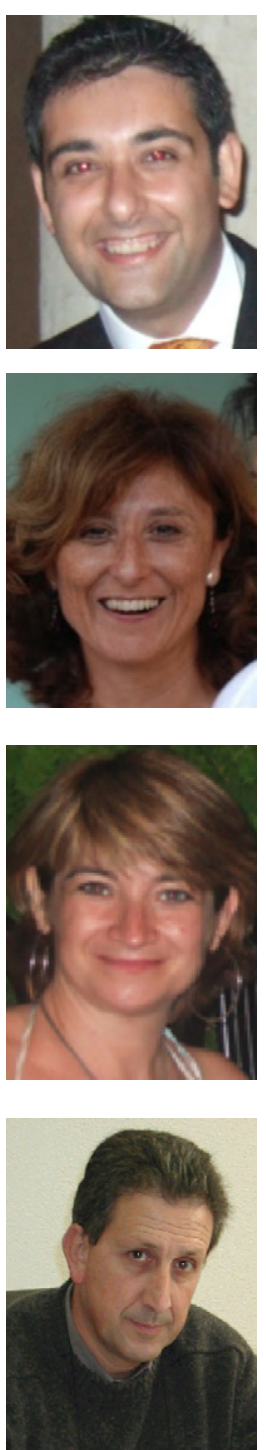

Cristina Pinedo Rivilla studied biochemistry at the University of Sevilla, where she graduated in 2004. After studying a M.S. in microbial biotechnology in 2008, she received her Ph.D. degree in 2009 under the supervision of Prof. Collado and Prof. Aleu Casatejada on the use of filamentous fungi as biocatalysts in the preparation of enantiomerically pure compounds and the enantioselective biocatalytic synthesis of bioactive molecules. She is currently a postdoctoral student at the University of Cádiz, Department of Organic Chemistry, and her current research interests are directed towards the putative role of the phytotoxins excreted by Botrytis cinerea in the infection mechanism and the design of new selective

Antonio J. Bustillo Pérez studied chemistry at the University of Cádiz, where he graduated in 1999. He received his Ph.D. degree in 2006 under the supervision of Prof Aleu and Prof. Hernández-Galán on biocatalytic synthesis of selective fungicides. He is currently working at Bodegas Garvey (Jerez de la Frontera) as Head of the laboratory of chemistry.

Hernández Galán obtained her Ph.D. Degrees from the University of Cádiz in 1991 for her work on the synthesis of 3-(1,1-dimethylallyl)coumarins under the tutelage of Professor F.R. Luis. She completed her Ph.D. studies at the Dyson Perrins Laboratory, Oxford with Professor Laurence M. Harwood. She is currently Professor of Organic Chemistry at the University of Cádiz. Her current research interest includes the biosynthesis of natural products and synthesis of bioactive compounds.

osefina Aleu Casatejada studied chemistry at the University of Cádiz, where she graduated in 1991. After working with Prof. J.R. Hanson at the Sussex University for several months in 1995, she received her Ph.D. degree in 1996 under the supervision of Prof. Collado on design of selective fungicides. She then worked for 15 months as a postdoctoral fellow with Prof. C. Fuganti at Politecnico di Milano (Italy) on biocatalytic synthesis of flavours. She is currently a senior lecturer of organic chemistry at the University of Cádiz and her current research interests are directed towards the biocatalytic synthesis of bioactive molecules and design of selective fungicides.

Isidro G. Collado is a professor of organic chemistry at the University of Cadiz, Andalucia, Spain. He received a B.Sc. in chemistry from the University of Seville in 1978. After working for one year at Facultad de Ciencias of Cadiz University on the synthesis of pyrrole derivatives, he completed his Ph.D. on natural product chemistry. He then worked as a postdoctoral fellow with the Professors B.M Fraga and J. R. Hanson on gibberellins chemistry at Consejo Superior de Investigaciones Científicas (Tenerife) and Sussex University, respectively. His current research interests include the synthesis of bioactive molecules and design of selective fungicides. 